\title{
ANALISIS PENGEMBANGAN SEKTOR PARIWISATA DAN EKONOMI KREATIF DI KOTA SAMARINDA
}

\section{(ANALYSIS OF THE DEVELOPMENT OF THE TOURISM SECTOR AND CREATIVE ECONOMY IN THE CITY OF SAMARINDA)}

\author{
Muhammad Tommy Fimi Putra \\ IKIP PGRI KALIMANTAN TIMUR \\ Jl. Suwandi Blok.B No.48. Samarinda \\ E-mail: tommy.fimi@gmail.com
}

Diterima: 25 Oktober 2021; Direvisi: 7 Desember 2021; Disetujui: 30 Desember 2021

\begin{abstract}
This study aims to analyze the development of the tourism sector and the creative economy in Samarinda City to increase the contribution of the tourism and creative economy sectors to economic resilience both at the regional and national levels. The implementation locations are in 10 sub-districts in Samarinda City, namely: 1) Sungai Kunjang District, 2) Samarinda Ulu District, 3) North Samarinda District, 4) Samarinda Ilir District, 5) Samarinda Seberang District, 6) Palaran District, 7) Samarinda District. Kota, 8) Loa Janan Ilir District, 9) Sambutan District and 10) Sungai Pinang District. The methodology used is descriptive qualitative approach using an interactive analysis model from Miles and Huberman. The results of the analysis found that each sub-district has different characteristics in the concentration of tourist destinations, but from the average these destinations are only existing destinations that have large capital that have developed while destinations have not developed the potential for the future is very large to be developed by increasing 4 A (attraction, accessibility, amenity and ancilliary) where almost all new undeveloped tourist destinations in Samarinda City have the same problems, while creative economy development requires the development of Empowerment of Creative Economy actors in order to increase their income, Increased financing for Creative Economy businesses so that can increase business development for Creative Economy players, the need for the provision of adequate and competitive infrastructure - technology to support the development of creativity, so that it is expected to be able to develop Creative Economy in Samarinda City.
\end{abstract}

Keywords: Development, Tourism, Economy, Creative.

\begin{abstract}
ABSTRAK
Kajian ini bertujuan untuk menganalisis pengembangan sektor kepariwisataan dan ekonomi kreatif di Kota Samarinda untuk meningkatnya kontribusi sektor pariwisata dan ekonomi kreatif terhadap ketahanan ekonomi baik dalam tingkat daerah maupun tingkat nasional. Lokasi pelaksanaanya berada pada 10 Kecamatan di Kota Samarinda yaitu: Kecamatan Sungai Kunjang, Samarinda Ulu, Samarinda Utara, Samarinda Ilir, Samarinda Seberang, Palaran, Samarinda, Loa Janan Ilir, Sambutan dan Sungai Pinang. Metodelogi yang digunakan adalah deskriptif kualitatif dengan melakukan pendekatan menggunakan model analisis interaktif dari Miles dan Huberman. Hasil analsis ditemukan bahwa tiap masing-masing Kecamatan memiliki karakteristik yang berbeda dalam konsentrasi destinasi wisatanya tetapi dari rata-rata destinasi tersebut hanya pada destinasi yang eksisting yang memiliki modal besar yang telah berkembang sedangkan destinasi belum berkembang potensinya kedepan sangat besar untuk dikembangkan dengan cara meningkatkan 4 A (attraction, accessibility, amenity dan ancilliary) yang dimana hampir seluruh destinasi wisata baru yang belum berkembang yang ada di Kota Samarinda memiliki permasalahan yang sama sedangkan pengembangan ekraf perlu adanya pengembangan Pemberdayaan pelaku Ekraf agar dapat meningkatkan penghasilannya, Peningkatan pembiayaan bagi usaha Ekonomi Kreatif sehingga dapat menambah perkembangan usaha bagi pelaku Ekraf, perlunya penyediaan
\end{abstract}


infrastruktur teknologi yang memadai dan kompetitif untuk mendukung berkembangnya kreativitas, sehingga diharapkan dapat mengembangkan ekraf di Kota samarinda.

Kata Kunci: Pengembangan, Pariwisata, Ekonomi, Kreatif.

\section{PENDAHULUAN}

Berdasarkan Undang-Undang Nomor 10 Tahun 2009 tentang Kepariwisataan, pembangunan kepariwisataan meliputi industri pariwisata, destinasi pariwisata, pemasaran dan kelembagaan kepariwisataan dan Undang-Undang Nomor 24 Tahun 2019 tentang Ekonomi Kreatif menyebutkan bahwa pengembangan ekonomi kreatif dilakukan melalui pengembangan riset; pengembangan pendidikan; fasilitasi pendanaan dan pembiayaan; penyediaan infrastruktur; pengembangan sistem pemasaran; pemberian insentif; fasilitasi kekayaan intelektual; dan pelindungan hasil kreativitas.

Berkaitan dengan Ekraf dan Pariwisata diatas dapat kita simpulkan bahwa kegiatan dalam ekraf dan pariwisata saling berhubungan satu dengan lainnya, berdasarkan Undang-Undang Kepariwisataan dan Ekraf disetiap daerah harus ada pengembangnnya mengingat pada UndangUndang tersebut menjelaskan adanya riset pengembangan apakah itu pendidikan, pendanaan dan lain-lain sehingga ekraf dan pariwisata dapat berkembang di seluruh daerah di Indonesia.

Selain itu sangat berkembangannya potensi pariwisata sangat diharapkan dapat menambah penghasilan di masyarakat, karena pariwisata dan ekraf adalah bentuk kegiatan yang merupakan sektor sumber daya alam atau buatan yang tidak akan habis atapun dapat berkelanjutan berbeda dengan sumberdaya alam yang tidak dapat diperbarui seperti pertambangan, gas atau minyak mentah itu akan sangat terbatas dan tidak dapat diolah kembali sehingga anak cucu tidak akan dapat merasakan dapat pengelolaan sumber daya alam yang sifatnya suistanabel, bentuk ekraf dan pariwisata sangat diunggulkan karena dapat menjangkau dihampir seluruh aspek kehidupan kita sehari-hari sehingga potensi itu ada dan masyarakat cukup

Kota samarinda memiliki beragam jenis pariwisata yang cukup lengkap seperti pariwisata religi, kuliner, alam, bahari, belanja sampai dengan wisata malam dan wisata-wisata lainya di dukung dengan 17 Sub sektor kegiatan ekonomi kreatif lainnya seperti Kriya, aplikasi dan game, seni pertunjukan, fotografi, videografi, musik dll, yang di sajikan secara lengkap pada Gambar 1.

Selain itu untuk fasilitas sarana pendukung lainnya seperti Kost, Kostel, Apetermen dan Hotel sudah banyak di Kota Samarinda (dispar.samarinda.go.id). Sehingga kedepannya agar pengembangan pariwisata dan ekonomi kreatif dapat menghasilkan kolaborasi yang maksimal dan saling mendukung untuk menghasilkan hubungan yang sinergis mutualisme sehingga dapat mewujudkan tercapai visi Pariwisata di Kota Samarinda sekaligus dapat meningkatkan multiplier effect yang dihasilkannya dalam rangka mendukung tercapainya Visi pembangunan pariwisata dan ekonomi kreatif Provinsi Kalimantan Timur dan Nasional sehingga perlu dilakukan analisis strategi pengembangan di sektor pariwisata dan ekonomi kreatif di Kota Samarinda.

Dalam rangka terciptanya konsistensi dan keberlanjutan pengembangan pariwisata dan ekonomi kreatif di Kota Samarinda maka kajian ini dilaksanakan dengan mengacu pada dokumen perencanaan pariwisata dan ekonomi kreatif yang sudah disusun dan berupaya untuk menyusun strategi dan desain pengembangan pariwisata dan ekonomi kreatif secara lebih detail khususnya bagi pengembangan beberapa destinasi pariwisata unggulan di Kota Samarinda sehingga : 1) tercipta optimalisasi potensi wisata daerah, 2) berkembangnya ekonomi kreatif dengan memanfaatkan keane-karagaman seni budaya dan kearifan lokal, 3) terbentuknya kemitraan yang lebih strategis dan kuat antar pelaku pariwisata dan Pelaku ekonomi kreatif, 4) maju dan berkembangnya UKM untuk menunjang kualitas daya tarik wisata serta 5) 
tersedianya informasi pilihan paket destinasi wisata yang memudahkan wisatawan merencanakan perjalanannya.

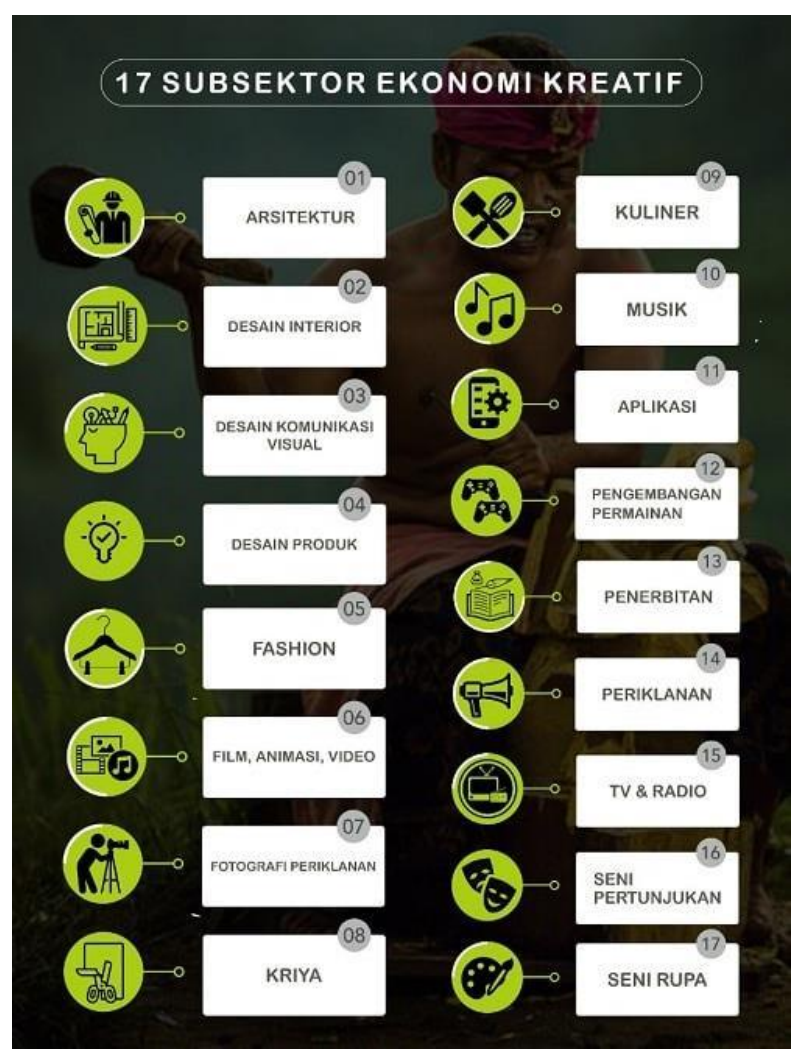

Gambar 1.

Sub Sektor Ekraf

\section{TINJAUAN PUSTAKA}

\section{Aspek Kepariwisataan}

Berkaitan dengan Daya Tarik Wisata, Cooper et al. (1995: 81) menyatakan bahwa terdapat 4 (empat) komponen yang harus dimiliki oleh sebuah objek wisata, yaitu: attraction, accessibility, amenity dan ancilliary.

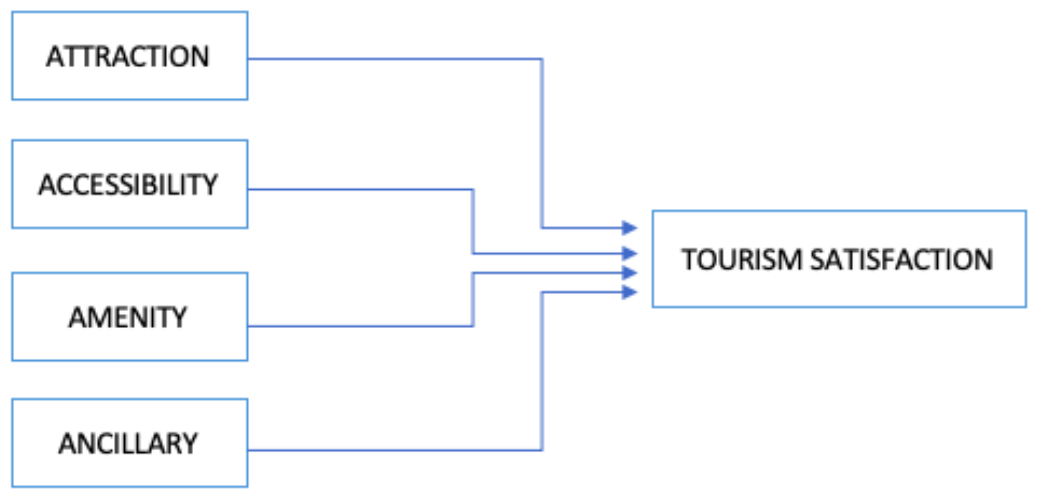

Gambar 2.

Komponen objek wisata

\section{Attraction (Atraksi)}

Merupakan daya tarik wisatawan saat berkunjung, dimana moment ini tidak dapat ditemukan dilokasi mana pun Karena atraksi merupakan sesuatu yang khas yang dimana setiap lokasi wisata harus memilikinnya. Bentuk atraksi ada tiga, yaitu: 
1. Natural Resources (alami)

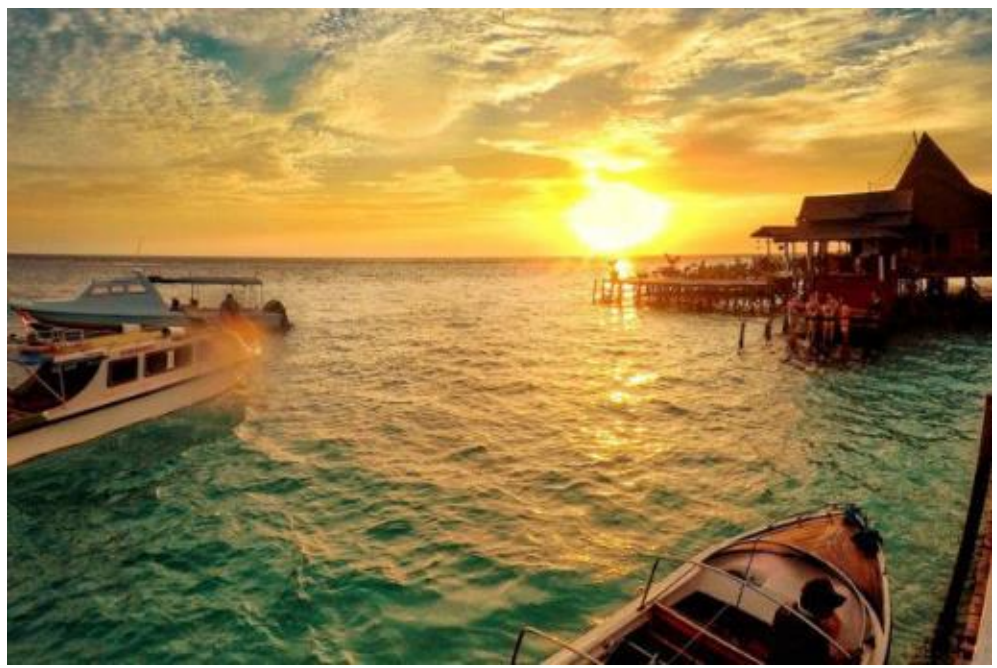

Gambar 3.

Bentuk Atraksi Wisata Alam

2. Wisata Adat Budaya

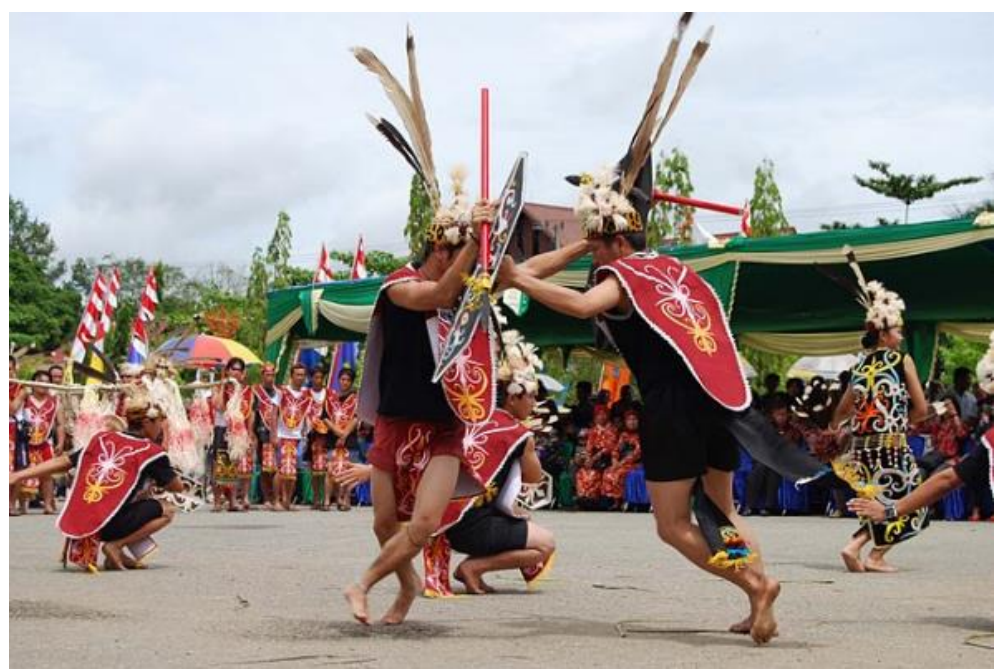

Gambar 4.

3. Atraksi Buatan

Bentuk Atraksi Wisata Budaya (Tarian)

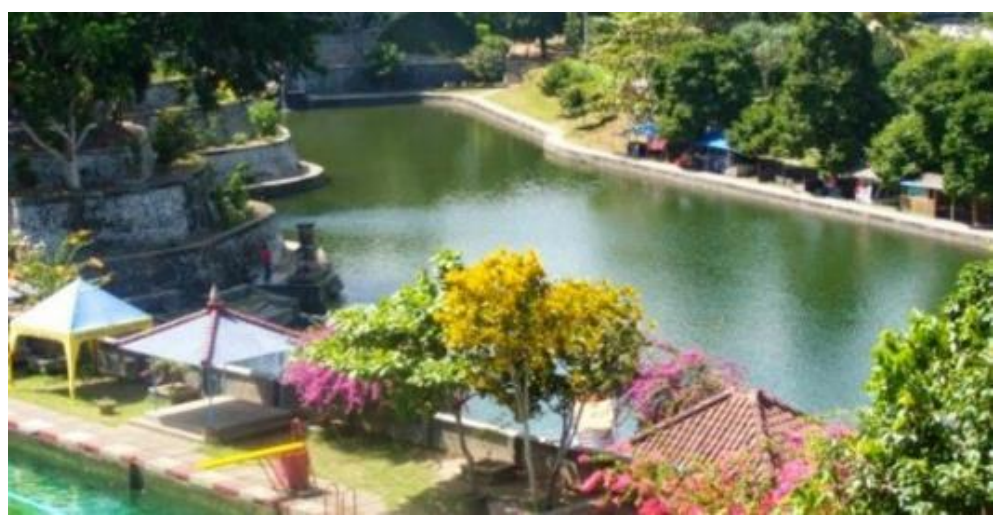

Gambar 5.

Bentuk Wisata Buatan (Taman) 


\section{Amenity (Fasilitas)}

Merupakan sarana prasarana yang harus dipersiapkan pada saat berkunjung di sebuah objek wisata dimana Amnitas sangat dibutuhkan wisatawan saat ingin fokus untuk berwisata dengan menikmati suasana dengan penuh waktu untuk seharian berwisata agar lebih nyaman dan mudah. Sarana dan prasarana yang dimaksud seperti: penginapan, rumah makan, transportasi dan agen perjalanan.

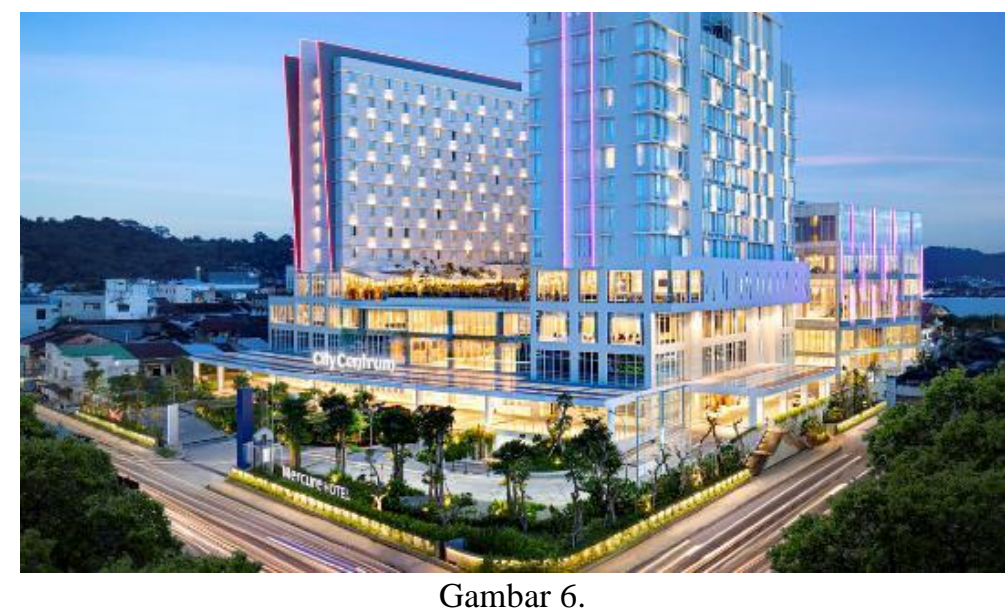

Fasilitas sarana prasarana pariwisata (Hotel)

\section{Accessibility (Aksesibilitas)}

Merupakan sebuah dukungan untuk memudahkan para wisatawan untuk berkunjung ke sebuah destinasi wisata, semakin lengkap aksesbilitasnya maka semakin besar pula antusias wisatawan dalam menggunakan berbagai macam pilihan baik itu laut, udara, darat dan sungai.

Ancilliary (Pelayanan Tambahan)

Diharapkan semua Wadah wisata memiliki pelayanan tambahan dikarenakan adakan sangat memudahkan wisatawan untuk mendapatan informasi terkait kepariwisataan terutama wisatawan yang baru berkunjung di wilayah yang baru dikunjunginya agar mendapatkan informasi yang jelas dan memudahkan dalam pelayanan untuk menunjang sektor kepariwisataan. Pelayanan yang disediakan termasuk pemasaran, pembangunan fisik (jalan raya, rel kereta, air minum, listrik, telepon, dan lain-lain).

Ancilliary juga mencakup hal-hal yang mendukung sebuah kepariwisataan, seperti lembaga pengelolaan, Tourist Information, Travel Agent dan stakeholder yang berperan dalam kepariwisataan.

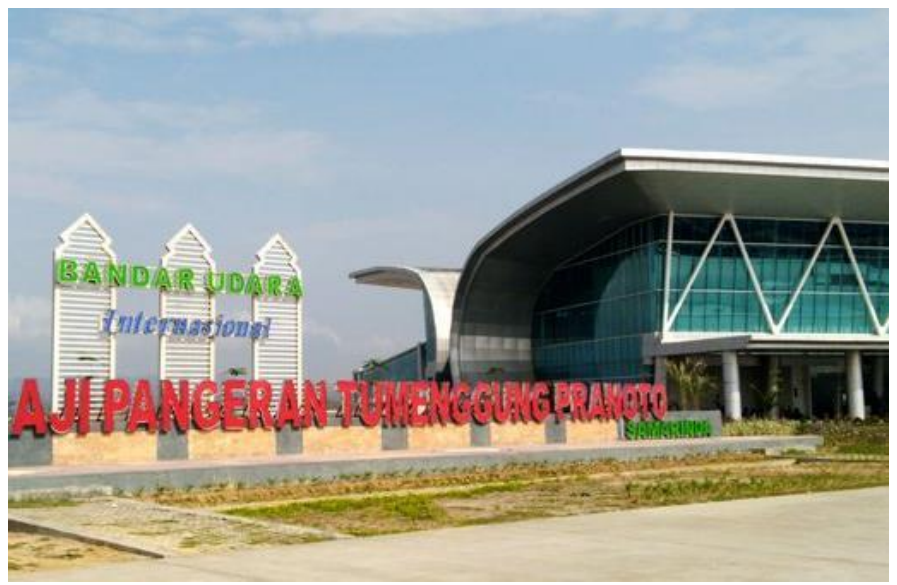

Gambar 7.

Fasilitas Aksesbilitas (Bandara) 


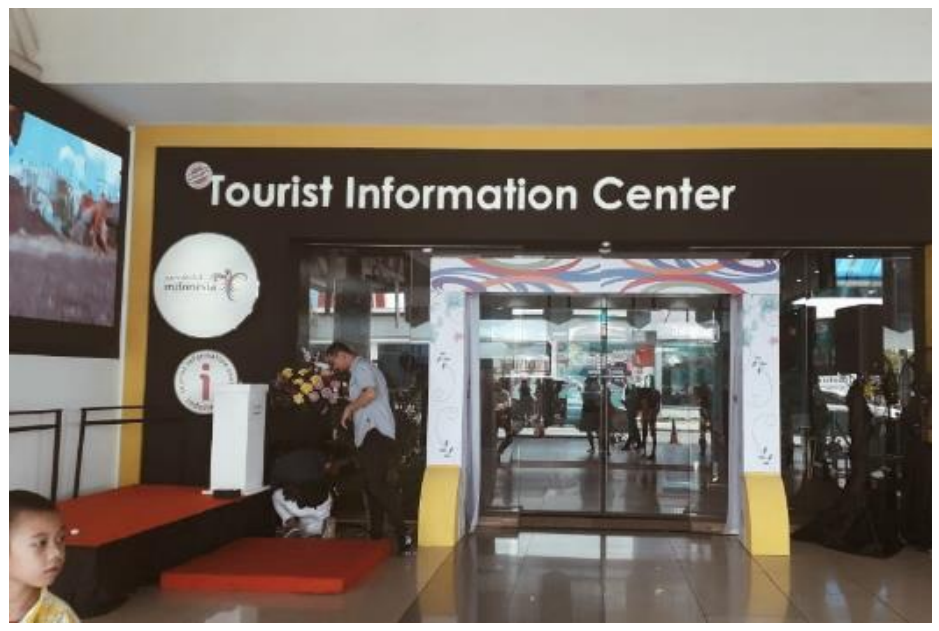

Gambar 8.

Pusat Informasi Pariwisata (Tourist Information Center)

\section{Aspek Ekonomi Kreatif}

Profil ekonomi kreatif

Profil ekonomi kreatif didapatkan dari pengumpulan data, analisis ekosistem ekonomi kreatif dan aktor kreatif. Profil ekonomi kreatif memuat data-data kuantitatif dan kualitatif yang mampu menggambarkan kondisi ekonomi kreatif daerah saat ini secara detail.

Data yang telah dikumpulkan pada saat penyusunan profil ekonomi kreatif dapat dibuat menjadi dasar identifikasi tantangan dan peluang dalam mengembangkan ekonomi kreatif daerah.

Strategi dan desain pengembangan ekonomi kreatif merupakan langkah-langkah yang berisikan program-program pengembangan ekonomi kreatif indikatif untuk mewujudkan visi dan misi pengembangan ekonomi kreatif Kota Samarinda yang mengacu pada Arah Kebijakan, Strategi dan Sasaran pada lampiran Perpres Rindekraf. Untuk menentukan tiga hal ini, perlu ada pembahasan lintas Perangkat Daerah terkait subsektor prioritas yang akan dikembangkan di sesuai dengan potensi dan kebutuhan, memiliki kemungkinan sukses tinggi, value added tinggi serta mampu memberikan multiplier effect untuk pertumbuhan subsektor lainnya.

\section{Tinjauan Ekonomi Kreatif secara Teoritis}

Globalisasi dan perdagangan global merupakan suatu hal yang tidak terelakkan dari kemajuan teknologi. Dampaknya terjadi perubahan besar dalam lanskap kehidupan manusia. Renald Kasali (2017) menyebutnya sebagai era disruption. Tak adaptip maka akan terhempas. Hal ini juga ditandai dengan kaburnya batas-batas wilayah karena satu wilayah dapat terhubung dengan wilayah lainnya dalam satu waktu yang sama.

Salah satu dampak disrupsi dengan muncul bisnis pendatang baru yang dapat menyerap tenaga kerja dengan dukungan teknologi informasi. Ekonomi kreatif telah dikembangkan di berbagai negara dan menampilkan hasil positif yang signifikan, antara lain berupa penyerapan tenaga kerja, penambahan pendapatan daerah, hingga pencitraan wilayah di tingkat internasional.

Ekonomi Kreatif merupakan perwujudan nilai tambah dari suatu ide atau gagasan kekayaan intelektual yang mengandung keorisinilan, lahir dari kreativitas intelektual manusia, berbasis ilmu pengetahuan dan teknologi, keterampilan, serta warisan budaya.

Adapun bila mengacu pada Peraturan Presiden Nomor 142 Tahun 2018 tentang Rencana Induk Pengembangan Ekonomi Kreatif Nasional Tahun 2018 - 2025, Peraturan Presiden Nomor 96 Tahun 2019 tentang Kementerian Pariwisata dan Ekonomi Kreatif, Kamus Besar Bahasa Indonesia dan Publikasi Kementerian Pariwisata dan Ekonomi Kreatif dengan judul "Ekonomi Kreatif Kekuatan Baru Indonesia Menuju 2025, menetapkan sub sektor ekonomi 
kreatif sebagai berikut : 1) aplikasi dan game developer, 2) arsitektur, 3) desain interior, 4) desain komunikasi virtual, 5) desian produk, 6) fashion, 7) film, animasi dan vidio,8) fotografi, 9) kriya, 10) kuliner, 11) musik, 12) penerbitan, 13) periklanan, 14) seni 15) pertunjukan dan 16) seni rupa.

Definisi Sektor Ekonomi Kreatif dan Sub Sektor Ekonomi Kreatif (Mengacu pada Perpres No. 96/2019, Perpres 142/2018, KBBI dan Publikasi Kementerian Pariwisata dan Ekonomi Kreatif: "Ekonomi Kreatif: Kekuatan Baru Indonesia Menuju 2025, Rencana Aksi Jangka Menengah 2015- 2019”): Ekonomi Kreatif: perwujudan nilai tambah dari suatu ide atau gagasan kekayaan intelektual yang mengandung keorisinalan, lahir dari kreativitas.

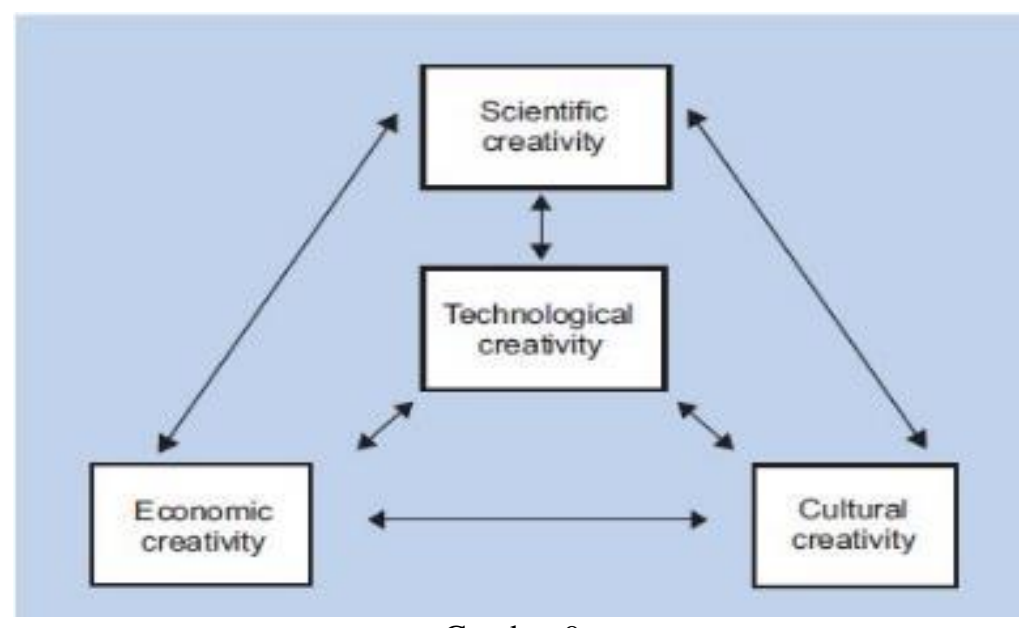

Gambar 9.

Bagan Rumusan Ekonomi Kreatif Sumber: UNDP (2008)

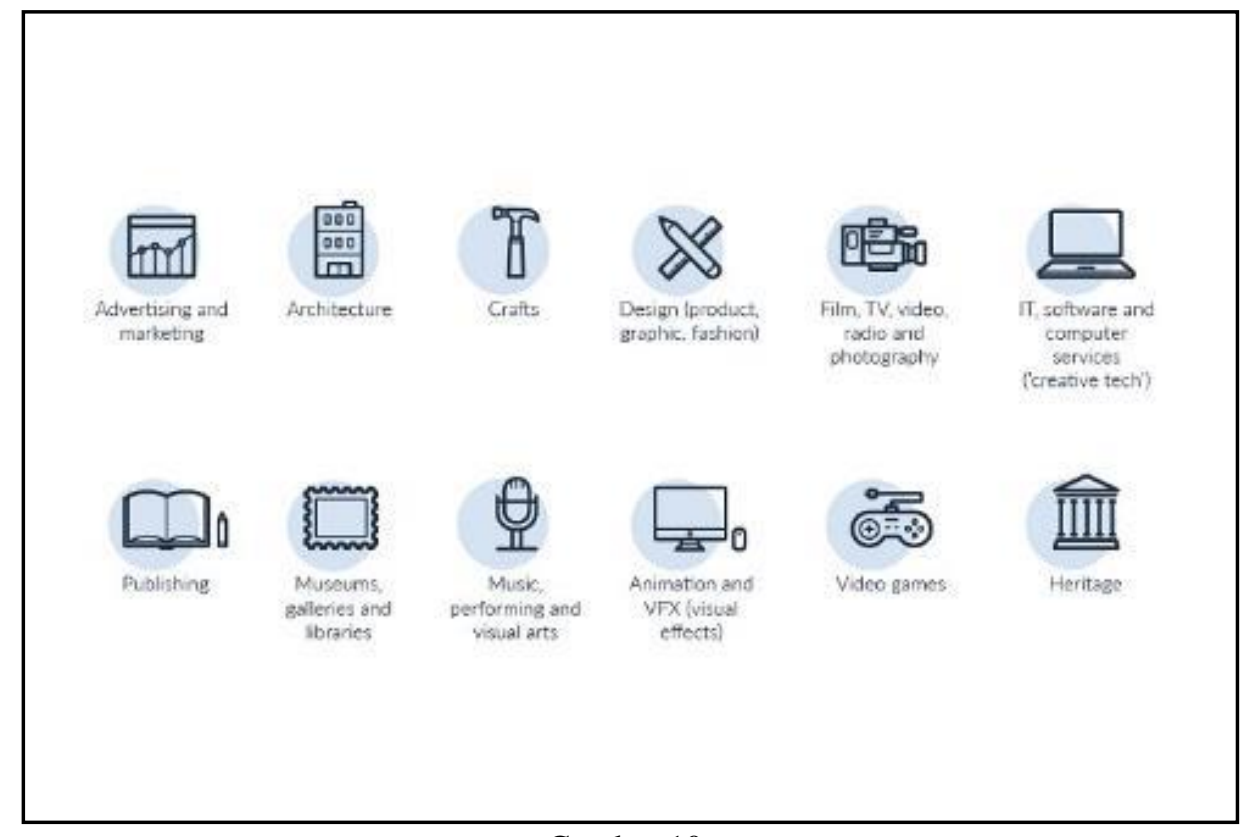

Gambar 10.

Simbol Ekonomi Kreatif 


\section{METODE}

\section{Pengumpulan Data}

Data yang dikumpulkan adalah data data sekunder dan data primer. Data sekunder diperlukan meliputi peraturan perundang-undangan yang berlaku, dokumen perencanaan, rencana strategis dan laporan tahunan kementerian dan Organisasi Perangkat Daerah (OPD), profil daerah, literatur dan laporan kajian yang sudah dilakukan dan lain-lain, yang ada relevansinya dengan studi yang dilakukan.

Data primer diperoleh melalui:

1) Wawancara secara mendalam dengan menggunakan kuisioner kepada responden kunci (Keys Person) yang dianggap dapat memberikan informasi terkait pariwisata dan ekonomi kreatif di Kota Samarinda

2) Pengamatan langsung/observasi di lapangan ke lokasi daya tarik wisata dan ekonomi kreatif. Responden dalam kajian ini antara lain:

1) Aparatur pada OPD terkait baik ditingkat Kota maupun kecamatan,

2) Pelaku/pengelola pariwisata dan ekonomi kreatif, kelompok masyarakat sadar wisata, tokoh masyarakat dan tokoh adat, serta wisatawan.

Informasi utama yang diharapkan dapat diperoleh dari wawancara antara lain program dan kegiatan yang sudah dilaksanakan dan yang akan dilaksanakan, kendala/permasalahan yang dihadapi, potensi pariwisata dan ekonomi yang dimiliki yang dapat dikembang, kondisi eksisting daya tarik wisata dan ekonomi kreatif, respon dan dukungan masyarakat terhadap pengembangan pariwisata dan ekonomi kreatif, potensi seni budaya yang dapat dimanfaatkan untuk mendukung kegiatan kepariwisataan dan ekonomi kreatif serta kesan dan harapan pengunjung/wisatawan terkait daya tarik wisata yang pernah dan sedang dikunjungi.

\section{Teknik Analisis Data}

Teknik analisis data yang digunakan dalam kajian ini adalah analisis deskriptif kualitatif dengan melakukan pendekatan menggunakan model analisis interaktif dari Miles dan Huberman tahun 1979 (Denzin et al :2009:592), yang mencakup pengumpulan data, reduksi data, penyajian data, dan penarikan kesimpulan.

\section{HASIL DAN PEMBAHASAN}

Berdasarkan hasil sebaran kuesioner kepada para responden yang ada di 10 kecamatan seperti Kecamatan Sungai Kunjang, Samarinda Ulu, Samarinda Utara, Samarinda Ilir, Samarinda Seberang, Palaran, Samarinda, Loa Janan Ilir, Sambutan dan Sungai Pinang. Analisis pengembangan kepariwisataan ini didasari pada upaya untuk memanfaatkan atau mengembangkan potensi yang dimiliki maupun upaya mengatasi permasalahan sehingga dapat dirumuskan strategi yang diharapkan dapat mengoptimalkan potensi yang dimiliki dan mengatasi atau minimal mengurangi permasalahan yang menjadi penyebab tidak atau kurang berkembangnya destinasi wisata.

Berdasarkan hasil wawancara dengan responden kunci baik dari organisasi perangkat daerah terkait, unsur aparatur kecamatan, pengelola destinasi wisata dan responden lainnya serta setelah melalui observasi lapangan pada destinasi wisata maka dirumuskan beberapa pengembangan yang diharapkan dapat mempercepat optimalisasi pengembangan destinasi pariwisata sekaligus sebagai dasar dalam penysunan indikasi program dan kegiatan, sebagai berikut:

1. Meningkatkan aksesibilitas menuju destinasi wisata.

2. Menyediakan angkutan sungai dan darat reguler terjadwal ke lokasi destinasi wisata.

3. Mengintensifkan promosi daya tarik wisata memanfaatkan media promosi berbasis teknologi informasi. 
4. Pembangunan dan perbaikan fasilitas pendukung di lokasi destinasi wisata

5. Meningkatkan kualitas SDM pengelola destinasi wisata dan pelaku usaha pariwisata

6. Penguatan kelembagaan Pariwisata

7. Peningkatan peran dan kesadaran masyarakat pentingnya Pariwisata

8. Mendorong terjalinnya kemitraan antara pengelola destinasi wisata dengan pemerintah, perusahaan.

9. Legalisasi destinasi dan desa wisata

10. Pelestarian dan pembinaan seni-budaya untuk mendukung dan meningkatkan daya tarik wisata.

11. Meningkatkan pengkajian pada destinasi wisata sejarah.

Sedangkan untuk sektor ekonomi kreatif seperti yang tersaji dalam Tabel 1 yang menjadi unggulan adalah Kuliner, Fesyen, Fotografi, Musik dan Desain Produk.

Tabel 1.

Hasil Persepsi Perankingan Industri Ekonomi Kreatif Kota Samarinda

\begin{tabular}{cc}
\hline Sub Sektor & Ranking \\
\hline Kuliner & 1 \\
Fesyen & 2 \\
Fotografi & 3 \\
Musik & 4 \\
Desain Produk & 5 \\
\hline
\end{tabular}

Sumber: Hasil Olahan Data Peneliti, 2020

Berdasarkan hasil data yang diperoleh pada daerah kecamatan yang dikunjungi perihal industri ekonomi kreatif, maka fokus hasil pengembangan yang ditemui baik oleh para pelaku dan penggiat ekonomi kreatif serta perwakilan dari pemerintah antara lain:

1. Pemberdayaan pelaku Ekonomi Kreatif.

2. Peningkatan pembiayaan bagi usaha Ekonomi Kreatif.

3. Penyediaan infrastruktur teknologi yang memadai dan kompetitif untuk mendukung berkembangnya kreativitas.

4. Peningkatan apresiasi masyarakat terhadap kreativitas dan hak kekayaan intelektual

5. Penyediaan infrastruktur dan teknologi yang memadai dan kompetitif bagi pengembangan usaha Ekonomi Kreatif.

6. Pengembangan kota kreatif untuk menggali, memanfaatkan, menumbuh kembangkan, mengelola dan mengkonservasi kreativitas sertamemanfaatkan ilmu pengetahuan dan teknologi, seni dan budaya untuk mengembangkan potensi lokal.

Kota Samarinda modal dasar (aset) yang besar dalam mengembangkan pariwisata dan ekonomi kreatif, paling tidak dilihat dari banyaknya destinasi wisata dan pendukungnya yang dimiliki dan tersebar di seluruh kecamatan. Namun karena posisinya tersebar dan antar destinasi wisata tersebut bisa jadi berbeda letak dan kondisi geografis suku dan budaya, sejarah masa lalu, sentuhan pembangunan, serta peran dan kesadaran masyarakat menyebabkan daya tarik, potensi dan permasalahan yang dihadapi dalam mengembangkan pariwisata di masing-masing destinasi wisata bisa jadi berbeda dengan destinasi lainnya.

Dalam penelitian ini lokasi sampel penelitian pada 10 kecamatan di Kota Samarinda yaitu: Kecamatan Sungai Kunjang, Samarinda Ulu, Samarinda Utara, Samarinda Ilir, Samarinda Seberang, Palaran, Samarinda, Loa Janan Ilir, Sambutan dan Sungai Pinang. Dari masing- 
masing Kecamatan memiliki karakteristik yang berbeda dalam konsentrasi destinasi wisatanya tetapi dari rata-rata destinasi tersebut hanya pada destinasi yang eksisting yang memiliki modal besar yang telah berkembang sedangkan destinasi belum berkembang potensinya kedepan sangat besar untuk dikembangkan dengan cara meningkatkan 4 A (attraction, accessibility, amenity dan ancilliary) yang dimana hampir seluruh destinasi wisata baru yang belum berkembang yang ada di Kota Samarinda memiliki permasalahan yang sama.

\section{KESIMPULAN}

Pengembangan sektor pariwisata memiliki karakter yang berbeda-beda di setiap Kecamatan. Pada dasarnya memiliki permasalahan yang sama terkhusus pada destinasi wisata yang belum berkembang dalam permasalahan yang ditemukan rata-rata permasalahan yang sama seperti aksesibilitas menuju destinasi wisata khsusnya destinasi wisata baru yang rata-rata masih rusak atau belum memadai, perlunya menyediakan angkutan sungai dan darat reguler terjadwal ke lokasi destinasi wisata, perlunya promosi daya tarik wisata memanfaatkan media promosi berbasis teknologi informasi, masih banyak kesiapan untuk pembangunan dan perbaikan fasilitas pendukung di lokasi destinasi wisata, harus meningkatkan kualitas SDM pengelola destinasi wisata dan pelaku usaha pariwisata agar dapat meningkatkan sektor pariwisatanya tersebut, perlunya penguatan kelembagaan Pariwisata agar saling sinergi antara pengelola pariwisata, harus adanya peningkatan peran dan kesadaran masyarakat pentingnya Pariwisata, selalu mendorong terjalinnya kemitraan antara pengelola destinasi wisata dengan pemerintah atau perusahaan swasta, setiap sektor Pariwisata harus membentuk legalisasi destinasi dan desa wisata, selalu melakukan pelestarian dan pembinaan seni-budaya untuk mendukung dan meningkatkan daya tarik wisata, dan selalu meningkatkan kajian pada destinasi wisata khususnya tentang sejarah Kota Samarinda.

\section{UCAPAN TERIMAKASIH}

1. Kepada Badan Penelitian dan Pengembangan Daerah Kota Samarinda yang telah memberikan kesempatan kepada saya dalam menerbitkan atrikel ini

2. IKIP PGRI KALIMANTAN TIMUR mewadahi dalam menyusun kegiatan kajian

3. Perangkat Kecamatan Sungai Kunjang, Samarinda Ulu, Samarinda Utara, Samarinda Ilir, Samarinda Seberang, Palaran, Samarinda, Loa Janan Ilir, Sambutan dan Sungai Pinang. serta OPD terkait seperti Dispar Samarinda, BPS,dst. yang telah membantu dilapangan dalam menyusun Kajian.

\section{DAFTAR PUSTAKA}

Ade W.P. dan Sri D.L (2021). Partisipasi MasyarakatDalam Pengelolaan Desa Wisata Tista. Vol. 9 No.1. Jurnal Destinasi Pariwisata.

Akagi, H., Kanazawa, Y., Nabae, A.’Instantaneous reactive power compensator comprising switching devices without energy storage components", IEEE Trans. Ind. Appl., 1984,I, (3), pp.625-630Undang-Undang Nomor 10 Tahun 2009 tentang Kepariwisataan

Cemporaningsih E.dkk (2020). Ekonomi Kreatif sebagai Poros Pengembangan Pariwisata di Kecamatan Kledung dan Bansari, Kabupaten Temanggung.Vol.12 No.2. Jurnal Nasional Pariwiasata

Cooper et al. (1995). Tourism: Principles and Practice. London: Pitman Publishing.

Denzin, Norman K. dan Yvonna S. Lincoln (eds.). 2009. Handbook of Qualitative Research. Terj. Dariyatno dkk. Jogjakarta: Pustaka Pelajar.

Lifa N.N dan Puspa A.W (2021). Pengembangan Ekowisata Berbasis Masyarakat Dalam Meningkatkan Daya Tarik Wisata Di Pemandian Kolam Penawar Atas Ketapang Banyuwangi.Vol6 No.1. Jurnal Pariwsata Pesona 
Millenia. J. dkk (2021). Strategi Pengembangan Wisata Mangrove Desa Sedari Berbasis Analisis 4A (Attraction, Accessibility, Amenities, Ancillary Services). Vol. 26 No.3. Jurnal Ilimah Pariwisata.

Peraturan Presiden Nomor 142 Tahun 2018 tentang Rencana Induk Pengembangan Ekonomi Kreatif Nasional Tahun 2018 - 2025

Perpres No. 96/2019, Perpres 142/2018, KBBI dan Publikasi Kementerian Pariwisata dan Ekonomi Kreatif: "Ekonomi Kreatif: Kekuatan Baru Indonesia Menuju 2025, Rencana Aksi Jangka Menengah 2015- 2019

Prana Y.W, dkk (2021). Implementasi Wisata Edukasi Di Agrowisata Doesoen Kakao Kecamatan Glenmore, Kabupaten Banyuwangi. Vol.9 No.1. Jurnal Destinasi Pariwisata.

Rhenald Kasali (2017). Manajemen Public Relations. Jakarta: PT Pustaka

Undang-Undang Nomor 10 Tahun 2009 tentang Kepariwisataan

Undang-Undang Nomor 24 Tahun 2019 tentang Ekonomi Kreatif

Yoeti, (1985). Pengantar Ilmu Pariwisata, Bandung: Angkasa 